\title{
Research Article \\ Study on the Phase Change Characteristics of Carbon-Based Nanofluids
}

\author{
Tun-Ping Teng $\mathbb{D}^{1},{ }^{1}$ Shang-Pang Yu $\mathbb{D}^{D},{ }^{2}$ Ting-Chiang Hsiao, ${ }^{1}$ and Chun-Chi Chung ${ }^{1}$ \\ ${ }^{1}$ Department of Industrial Education, National Taiwan Normal University, No. 162, Sec. 1, Heping E. Road, Da'an District, \\ Taipei City 10610, Taiwan \\ ${ }^{2}$ Department of Mechatronic Engineering, National Taiwan Normal University, No. 162, Sec. 1, Heping E. Road, Da'an District, \\ Taipei City 10610, Taiwan
}

Correspondence should be addressed to Tun-Ping Teng; tube5711@ntnu.edu.tw

Received 7 March 2018; Revised 1 May 2018; Accepted 4 June 2018; Published 8 July 2018

Academic Editor: Iftikhar Ali Sahito

Copyright (c) 2018 Tun-Ping Teng et al. This is an open access article distributed under the Creative Commons Attribution License, which permits unrestricted use, distribution, and reproduction in any medium, provided the original work is properly cited.

In this study, carbon-based nanofluids (CBNFs) with the minimized carbon materials (MCMs) were prepared using a graphite powder-based heating and cooling processing method (GP-HCPM). In addition, sodium dodecyl benzenesulfonate (SDBS) was added as a dispersant to enhance the stability of the CBNFs. Two methods, one involving fixed heating and cooling rates and the other involving fixed heating and cooling temperatures, were used to measure and analyze the phase change characteristics of the CBNFs and SDBS aqueous solution in order to evaluate the feasibility of employing CBNFs as phase change materials (PCMs) for cold storage applications. Results revealed that SDBS reduced the thermal conductivity $(k)$ and increased the viscosity $(\mu)$, density $(\rho)$, and specific heat $\left(c_{\mathrm{p}}\right)$ of the samples; the CBNFs tended to increase the $k, \mu$, and $\rho$ values but reduce the $c_{\mathrm{p}}$ values of the samples, compared with water. Furthermore, the SDBS aqueous solution and CBNFs significantly reduced the contact angle of droplets, compared with water. Phase change experiments conducted for all samples revealed that the CBNF sample S4 demonstrated the greatest reduction ratios in onset nucleation time, solidification time, and subcooling degree (38.98\%, 11.05\%, and $35.41 \%$, resp.); thus, S4 was determined to be the most suitable CBNF for use as a PCM in cold storage applications.

\section{Introduction}

Water is the most commonly used phase change material (PCM) for cold storage in ice storage air-conditioning systems, because of its low cost and substantial latent heat of freezing and melting. Ice storage air-conditioning systems work according to peak and off-peak power demand; therefore, they can be useful for power scheduling and power system optimization. Consequently, improving the performance of PCMs is a critical factor when improving the operational efficiency of ice storage air-conditioning systems $[1,2]$. Before freezing, the water temperature must first reach a particular temperature below the freezing temperature. Once this temperature is reached, the temperature is stabilized at approximately $0^{\circ} \mathrm{C}$ and the water starts to freeze. This temperature is the nucleation temperature $\left(T_{n}\right)$ or the subcooling temperature $\left(T_{\text {sub }}\right)$. The subcooling degree (SD) is defined as the difference between the freezing temperature and $T_{\text {sub }}$. That is, a higher $T_{\text {sub }}$ level means a lower SD. Water must reach $T_{\text {sub }}$ to undergo nucleation and become ice. Therefore, chillers must operate below $T_{\text {sub }}$ to induce freezing. Furthermore, $T_{\text {sub }}$ affects the evaporation temperature setting of a chiller; a higher evaporation temperature engenders higher chiller efficiency. Therefore, reducing the SD, nucleation time, and solidification time and elevating the latent heat of freezing are vital to improving the efficiency of ice storage air-conditioning systems.

Factors that affect the SD, nucleation time, and solidification time of a PCM include the type of nucleation (homogenous or heterogeneous), cooling rate, container surface roughness, and solid-liquid interface [3-5]. In general, heterogeneous nucleation occurs more easily than homogenous nucleation and allows the freezing process to occur at higher temperatures and with a shorter phase change time. 
To avoid the aforementioned factors negatively affecting the nucleation rate and SD, researchers have proposed several methods such as adding nucleating agents or undissolved impurities [6-12], changing the size and shape of the PCMs [13-15], inputting external energy (mechanical and ultrasonic vibration) $[16,17]$, increasing the thermal conductivity of the PCMs [18-20], reducing the kinematic viscosity of the PCM [20-23], encapsulating the PCMs [24], and using the porous structure and network of the PCM to enhance their energy storage performance $[25,26]$. Such methods can effectively suppress SD and improve the energy storage performance of PCMs. The most prevalent method is using nucleating agents to promote heterogeneous nucleation of PCMs to suppress SD and accelerate nucleation for cold storage. Nucleating agents are solid particles or crystals of materials that initiate crystallization but do not dissolve at the operational temperature. Although nucleating agents can suppress the SD of a PCM, they do not undergo a phase change during the phase change process. Therefore, nucleating agents do not contribute to the phase change heat of freezing and may reduce the freezing temperature [21, 27].

In recent years, numerous studies of carbon-based nanomaterials (CBNMs) such as nanocarbons, carbon nanotubes (CNTs), graphene (GN), and graphene oxide (GO) have been conducted, which indicate these materials have high thermal conductivity [28, 29], excellent heat transfer performance $[30,31]$, and low SD and freezing duration in phase change process [7-9, 11]. In addition, CBNMs have high stability and are nonperishable in liquids. Therefore, the use of CBNMs to make nanofluids and thermal applications is a worthwhile research direction. Chandrasekaran et al. [7] prepared nanofluid phase change material (NFPCM) by adding 0.1 wt.\% multiwall carbon nanotubes (MWCNT) in deionized (DI) water along with pseudomonas and sodium dodecyl benzene sulfonate (SDBS) as a nucleating agent and surfactant for cold storage. The phase change experiments were carried out by isothermal bath at bath temperatures of $-2^{\circ} \mathrm{C}$ and $-6^{\circ} \mathrm{C}$ with the NFPCM. The results demonstrated that the pseudomonas eliminated the SD of the NFPCM completely and the MWCNT resulted with the reduction in the freezing duration of 25\% in the case of NFPCM compared to that of water. The fraction of solidified mass revealed that $50 \%$ of phase change material (PCM) was frozen in $25 \%$ of the total freezing time for both the water and NFPCM. Li et al. [8] adopted the ultrahigh specific surface area of GN as an additive in DI water to reduce the SD of freezing water. SDBS was used to enhance the stability of the nanofluids. The phase change experiments for temperature profile and heat were conducted by isothermal bath $\left(-25^{\circ} \mathrm{C}\right)$ and differential scanning calorimeter (DSC), respectively. The results showed that only the addition of 0.020 wt. $\%$ of GN was needed to completely eliminate the SD. The GN nanofluids had less $\mathrm{SD}$ and shorter total freezing time compared to $\mathrm{SiO}_{2}$ and $\mathrm{TiO}_{2}$ nanofluids at the same concentration. The addition of SDBS could improve suspension stability of nanofluids and further reduce the $\mathrm{SD}$, but it also slightly increases the total freezing time. Liu et al. [9] prepared low concentration of GO nanosheet aqueous nanofluids without any dispersants as a PCM for cold storage. The SD of nanofluids with different concentrations was tested experimentally in an isothermal bath at $-15^{\circ} \mathrm{C}$. The results indicated that the SD could be reduced by $69.1 \%$, and the time to start nucleation was reduced by $90.7 \%$. Fan et al. [11] used DSC with various cooling rates to measure and analyze nonisothermal crystallization of CNT and GN nanoplatelet (GNP) aqueous nanofluids with various concentrations. The results showed that low concentration of CNTs or GNPs led to reduction of the $\mathrm{SD}$ up to $5^{\circ} \mathrm{C}$ because of the nucleating effect. The GNPs with large contact area conducted better than CNTs in facilitating heterogeneous nucleation, which greatly suppress crystal growth during the late phase of nonisothermal crystallization. However, the relatively low concentrations of CNTs nanofluids could accelerate crystallization up to nearly $37 \%$ at low cooling rate. From the above literatures, it can be known that the addition of a large specific surface area such as CNTs, GN, and GO in water has considerable benefits for reducing $\mathrm{SD}$ and increasing the freezing rate. However, the manufacturing costs of CNTs and GN are still quite high at present; therefore, there are still some obstacles to actually making large amounts of PCMs for cold storage.

In the present study, a graphite powder-based heating and cooling processing method (GP-HCPM) was used to produce carbon-based nanofluids (CBNFs) as PCMs. The production of CBNFs by GP-HCPM had the advantages of simple manufacturing equipment, mass and rapid production, low cost, and no need to add toxic chemical agents. Therefore, the GP-HCPM of the CBNMs and CBNFs has a relatively high applicability and scalability. The related fundamental characteristics of the CBNFs were measured and analyzed. Finally, methods involving a fixed cooling rate and fixed cooling temperature were used to conduct experiments on phase change characteristics to evaluate the feasibility of the CBNFs as PCMs for cold storage. Simultaneous use of the above two methods to evaluate the phase change characteristics will help people better understand the availability of PCMs under different cooling modes.

\section{Freezing Nucleation Theories and Sample Preparation}

2.1. Homogeneous and Heterogeneous Nucleation. Freezing nucleation can be divided into homogeneous nucleation and heterogeneous nucleation. The nuclei in homogeneous nucleation are uniformly present in the main phase (e.g., water). The appearance of nuclei is closely related to free energy variation. The total free energy variation of homogeneous nucleation occurs at the critical radius $\left(r^{*}\right)$ is called the critical free energy variation $\left(\Delta G_{\text {ho }}^{*}\right)$ [32-34]. When the nuclei of heterogeneous nucleation are preferentially present at the vessel surface, the undissolved particle interface, and other nonmain phase positions, it is termed heterogeneous nucleation. Most of the forms of freezing nucleation are heterogeneous nucleation. Water nucleated in a closed container or an ice-making coil is an example of heterogeneous nucleation [35]. As illustrated in Figure 1, nucleation occurs on a substrate interface and the nuclei formed are similar and hemispherical; the contact angle between the nuclei and the substrate interface on which they rest is $\theta$, and the change 


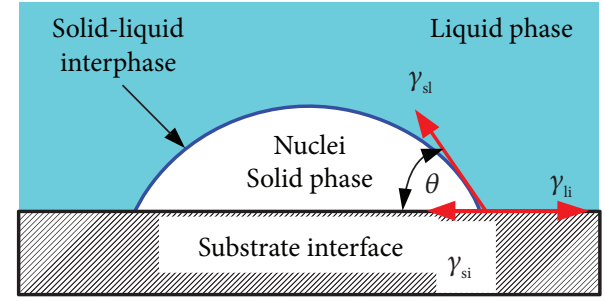

FIGURE 1: Schematic of heterogeneous nucleation.

in critical free energy when the nuclei are formed can be expressed as $\Delta G_{\text {he }}^{*}[32]$.

$$
\Delta G_{\mathrm{he}}^{*}=\Delta G_{\mathrm{ho}}^{*} \times S(\theta),
$$

where

$$
S(\theta)=\frac{\left[(2+\cos \theta)(1-\cos \theta)^{2}\right]}{4} .
$$

When heterogeneous nucleation occurs on the substrate interface, $S(\theta)$ is between 0 and 1. From (1) and (2), a lower $\theta$ value of the nuclei signifies less critical free energy at heterogeneous nucleation. This geometrical effect reduces the barrier, which increases the rate of nucleation as opposed to having a surface with a higher $\theta$ value $[35,36]$. Therefore, the critical free energy required for heterogeneous nucleation is smaller than that required for homogeneous nucleation. Water is more susceptible to nucleation and icing by heterogeneous nucleation than homogeneous nucleation at the same cooling temperature.

2.2. CBNF Preparation. In this study, a GP-HCPM was used for producing CBNF as a PCM. The GP-HCPM process for CBNF preparation is briefly described as follows (Figure 2) [37, 38]: $5 \mathrm{~g}$ of graphite powder (hexagonal graphite- $2 \mathrm{H}$; mean size: $3.2 \mu \mathrm{m}$ ) was heated in a stainless steel dipper at $600^{\circ} \mathrm{C}$ using an oxygen $\left(\mathrm{O}_{2}\right)$-acetylene $\left(\mathrm{C}_{2} \mathrm{H}_{2}\right)$ flame, and the red hot graphite powder was quickly transferred into cold water $\left(300 \mathrm{ml}, 3-5^{\circ} \mathrm{C}\right)$ in the sample collector for cooling to produce the CBNF. In this method, graphite powder was heated at a high temperature and then rapidly cooled in cold water; a slight explosion was thus produced on the graphite powder, which crushed the graphite powder to generate minimized carbon materials (MCMs) in the water. This process can be attributed to the rapid expansion and contraction resulting from the temperature difference between the graphite and water. The CBNF was then alternately dispersed using a stirrer hot plate (PC420D, Corning, USA), ultrasonic bath (5510R-DTH, Branson, USA), homogenizer (YOM300D, Yotec, Taiwan), and ultrasonic liquid processor (Q700, Qsonica, USA) to enhance the stability (dispersion and suspension performance) of the MCMs in the CBNF. Figure 3 exhibits field emission scanning electron microscope (FESEM) and transmission electron microscope (TEM) images of the MCMs. The generated MCMs were mostly irregular and flaky in appearance. The two-dimensional size (length $\times$ width) of these MCMs was determined using the FESEM and TEM images to be generally less than $1 \mu \mathrm{m}$; however, the thickness was less than $100 \mathrm{~nm}$. Therefore, the

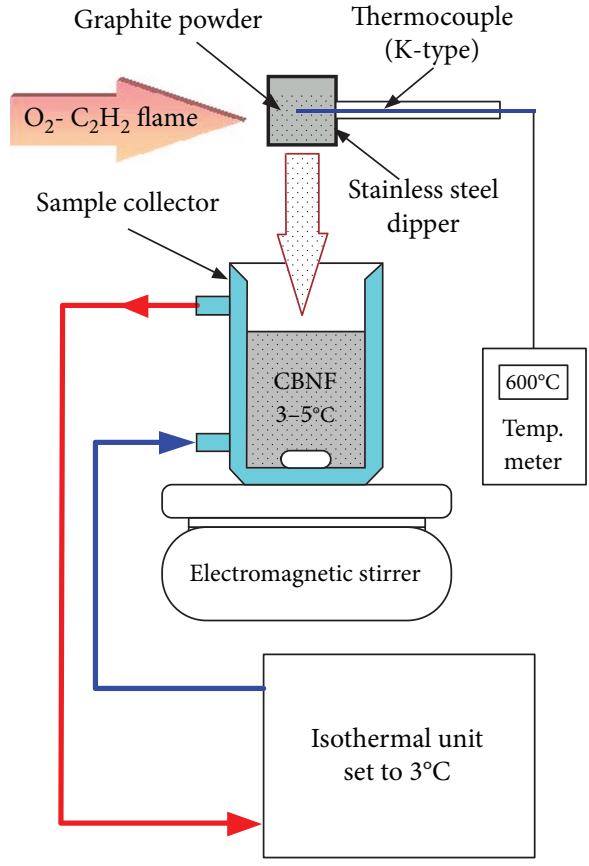

FIgURE 2: GP-HCPM process for CBNF preparation.

MCMs were considered nanomaterials. In addition, after $\mathrm{X}$-ray diffraction analysis, the main components of the MCMs were determined to be hexagonal graphite- $2 \mathrm{H}$, amorphous carbon, and a small amount of graphene oxide.

The original CBNF was diluted with water to obtain 1.2 wt.\% CBNF. 1.2 wt.\% CBNF was added with different concentrations $(0.06,0.12,0.24,0.48,0.96$, and 1.92 wt.\%) of SDBS (Sigma-Aldrich, USA) to form samples. Next, a spectrometer (V670, JASCO, Japan) was used to measure the differences in absorbance before and after the samples were left standing for 7 days to determine the optimal concentration of added SDBS. The experimental results showed that adding $0.48 \mathrm{wt} . \%$ SDBS to the CBNF had the best stability. A defoamer (DF, Antifoam B Silicone Emulsion, J. T. Baker, USA) at concentration of $25 \%$ of the weight of the added SDBS was used to suppress bubble formation. The determination of the concentration of the added DF was effective to suppress the foam of CBNF during stirring (stirrer was set at $400 \mathrm{rpm}$ ). The suspended mean particle size $\left(d_{\mathrm{p}}\right)$ and zeta potential $(\zeta)$ of the CBNF were tested using a nanoparticle analyzer (SZ-100, HORIBA, Japan). The $d_{\mathrm{p}}$ and $\zeta$ values of $1.2 \mathrm{wt} . \%$ MCMs in the CBNF with $0.48 \mathrm{wt} . \%$ SDBS were $1536.1 \mathrm{~nm}$ and $-63.3 \mathrm{mV}$, respectively. The particle size distribution of the CBNF presented a bimodal distribution with peak values of 212.8 and $6691.6 \mathrm{~nm}$, with the two peak distributions accounting for $80 \%$ and $20 \%$, respectively. However, because of the asymmetric morphology of suspended particles in liquid, using dynamic light scattering (DLS) to measure particle size usually results in overestimation of the particle size. Test results of $\zeta$ indicate that the CBNF had excellent stability $[39,40]$.

The 1.2 wt.\% CBNF with 0.48 wt.\% SDBS solution was further diluted with water to obtain 0.3, 0.6, and $0.9 \mathrm{wt} . \%$ CBNFs. The MCMs:SDBS weight ratio was $5: 2(1.2: 0.48)$ 


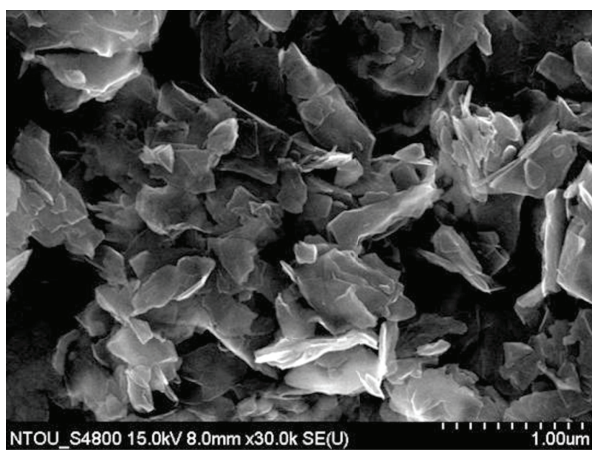

(a)

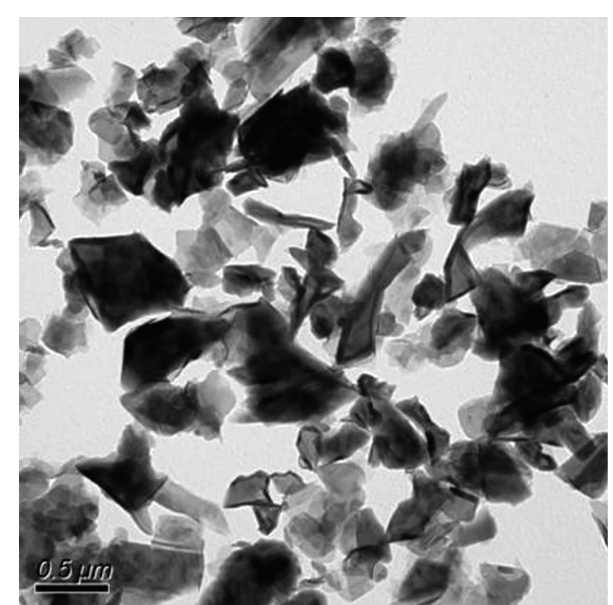

(b)

Figure 3: (a) FESEM and (b) TEM images of MCMs.

for all CBNFs, which demonstrated high stability and presented no observable solid-liquid separation even after undergoing static standing for over 45 days. The final experimental sample configuration is listed in Table 1. The final samples used in this experiment are used to evaluate the effect of SDBS and MCMs on the fundamental and phase change characteristic of CBNFs.

\section{Experimental Design and Procedures}

3.1. Fundamental Characteristic Experiments. The thermal conductivity $(k)$, viscosity $(\mu)$, and density $(\rho)$ of the samples were measured using a thermal property analyzer (KD-2 Pro, Decagon Devices, USA) with an accuracy of $\pm 5.0 \%$, a resonant viscometer (VL700-T15, Hydramotion, UK) with an accuracy of $\pm 1.0 \%$, and a liquid density meter (DA-130N, KEM, Japan) with an accuracy of $\pm 0.001 \mathrm{~g} / \mathrm{ml}$, respectively, in an isothermal unit (HW401L, HILES, Taiwan; accuracy: $\pm 0.5^{\circ} \mathrm{C}$ ) at $25^{\circ} \mathrm{C}$. The handheld measuring instruments were prone to deviation due to human factors. Therefore, the experiments were repeated 10 times, and the average of the five closest values was used as the test value to reduce experimental deviation.

The specific heat $\left(c_{\mathrm{p}}\right)$ of the samples was measured using a differential scanning calorimeter (DSC, Q20, TA, USA) with a mechanical refrigeration system (RCS40, TA, USA) in a high-purity nitrogen $(5 \mathrm{~N})$ atmosphere. The temperature and calorimetric accuracies of the DSC were $\pm 0.1^{\circ} \mathrm{C}$ and $\pm 1.0 \%$, respectively. An electronic pipette (5-100 $\mu \mathrm{l}$; Xplorer, Eppendorf, Germany) was used to draw a $12 \mu \mathrm{l}$ sample that was dripped into the sample pan (Tzero Pan: T100915), and then a precision electronic balance $(0.1 \mathrm{mg} / 42 \mathrm{~g}$, GR202, A\&D, Japan) was used to weigh the sample. The $c_{\mathrm{p}}$ test method is a standard reference approach, and the standard reference was pure water [41]. The experimental temperature ranged from 10 to $60^{\circ} \mathrm{C}$, and the heating rate was set at $10^{\circ} \mathrm{C} / \mathrm{min}$. The maximum deviation of the DSC measurement was mainly from weighing the sample. Therefore, the experiment for determining $c_{\mathrm{p}}$ was conducted five times for each sample, and the average of the three closest results was determined to obtain the $c_{\mathrm{p}}$ value of each sample, thereby reducing the effect of measurement deviations.

Each sample's $\theta$ was estimated by measuring a droplet of sample on the test substrate at room temperature and in ambient atmosphere using a video tensiometer (FTA188, First Ten Ångstroms, UK) with an experimental deviation of less than $1^{\circ}$. Due to the addition of SDBS to the sample, the $\theta$ value of the sample droplet was expected to be small. Therefore, the study adopted a glass substrate with a flat polyimide film tape attached on its surface to provide greater hydrophobicity in order to improve the identifiability and accuracy of the $\theta$ experiments. The experiment for determining $\theta$ was conducted five times for each sample, and the average of the results was determined to obtain the $\theta$ value of each sample.

3.2. Phase Change Experiments. The freezing and melting of water in an ice storage air-conditioning system are often referred to as charging and discharging processes. The phase change experiment in this study was conducted using two methods, one of which entailed fixed heating and cooling rates (method 1) and the other entailed fixed heating and cooling temperatures (method 2). Method 1 was conducted using the DSC; the instrument type, sampling method, sample size, and sample pan type were the same as those used for the $c_{\mathrm{p}}$ measurement. The experimental temperature ranged from -25 to $25^{\circ} \mathrm{C}$, and the heating and cooling rate was set at $10^{\circ} \mathrm{C} / \mathrm{min}$. Figure $4(\mathrm{a})$ illustrates the DSC endothermic and exothermic curves for water. The melting $\left(T_{\mathrm{mp}}\right)$ and solidification $\left(T_{\mathrm{sp}}\right)$ peak temperatures were the melting $\left(T_{\mathrm{m}}\right)$ and solidification $\left(T_{\mathrm{s}}\right)$ temperatures for the discharging and charging processes, respectively. The difference between $T_{\mathrm{mp}}$ and $T_{\mathrm{sp}}$ was defined as the SD of the sample $[18,22] . T_{\mathrm{ms}}$ was the starting temperature for melting. The area of discharging and charging peak was calculated by the test software (Universal Analysis 2000, TA, USA) to obtain the phase change heat of melting $\left(\Delta H_{\mathrm{m}}\right)$ and solidification $\left(\Delta H_{\mathrm{s}}\right)$. Each sample was tested five times, and the average of the three 
TABLE 1: Configuration of experimental samples.

\begin{tabular}{lccccccccc}
\hline \multirow{2}{*}{ Ingredient concentration (wt.\%) } & Water & S1BF & S2BF & S3BF & S4BF & S1 & S2 & S3 & S4 \\
\hline SDBS & 0 & 0.12 & 0.24 & 0.36 & 0.48 & 0.12 & 0.24 & 0.36 & 0.48 \\
MCMs & 0 & 0 & 0 & 0 & 0 & 0.3 & 0.6 & 0.9 & 1.2 \\
\hline
\end{tabular}

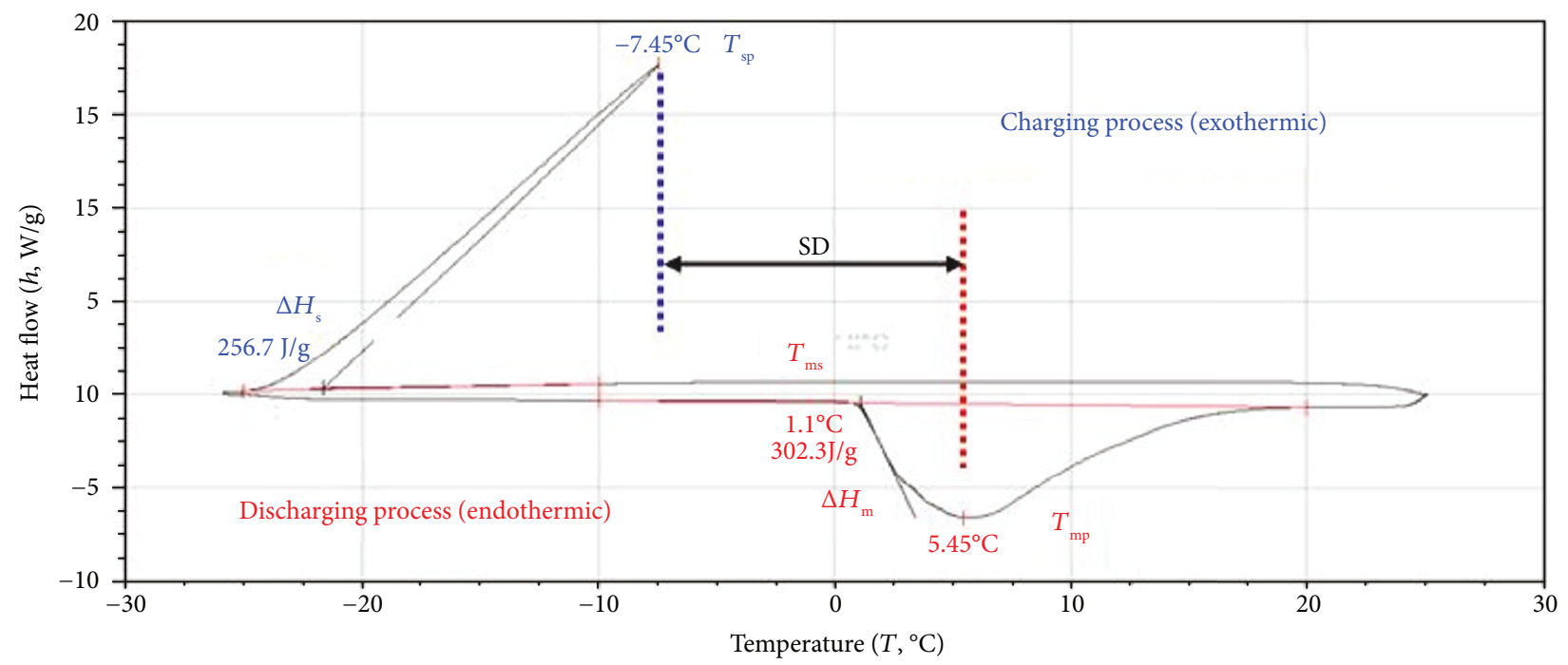

(a)

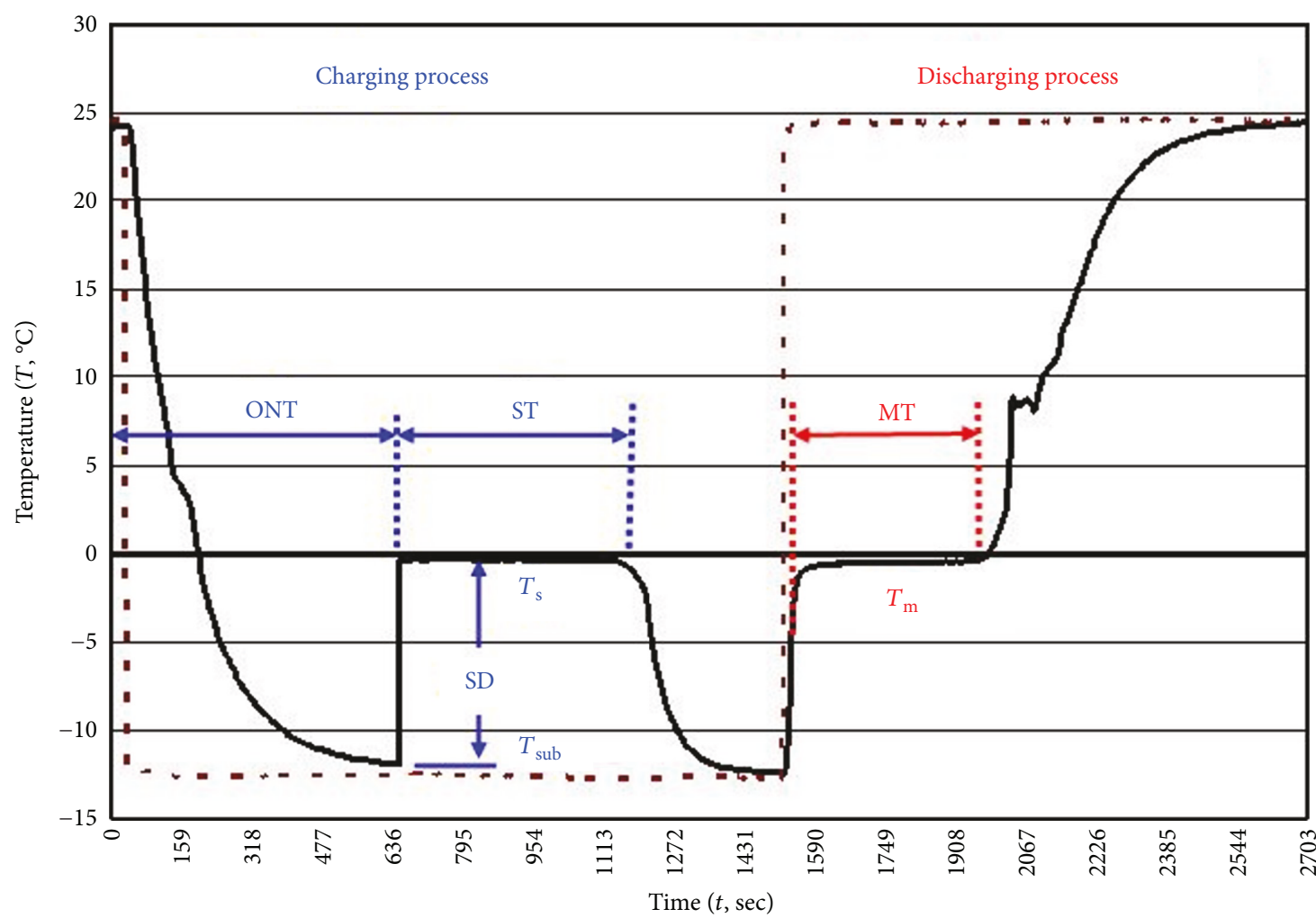

Water

-.--- Coolant

(b)

FIGURE 4: Charging and discharging curves of water obtained using (a) method 1 and (b) method 2. 
TABLE 2: Results from experiments conducted on fundamental characteristics of samples.

\begin{tabular}{lcccccccc}
\hline \multirow{2}{*}{ Number } & \multicolumn{4}{c}{ Experimental results } & \multicolumn{3}{c}{ Change ratio (\%) } \\
& $k\left(\mathrm{~W} / \mathrm{m}^{\circ} \mathrm{C}\right)$ & $\mu(\mathrm{mPa} \mathrm{s})$ & $\rho\left(\mathrm{kg} / \mathrm{m}^{3}\right)$ & $c_{\mathrm{p}}\left(\mathrm{kJ} / \mathrm{kg}^{\circ} \mathrm{C}\right)$ & $\mathrm{CR}_{k}$ & $\mathrm{CR}_{\mu}$ & $\mathrm{CR}_{\rho}$ & - \\
\hline Water & 0.606 & 0.88 & 997.16 & 4.183 & - & - & - \\
S1BF & 0.594 & 0.90 & 997.58 & 4.194 & -1.93 & 1.89 & 0.04 \\
S2BF & 0.584 & 0.92 & 998.38 & 4.207 & -3.58 & 3.77 & 0.12 & 0.58 \\
S3BF & 0.581 & 0.93 & 999.04 & 4.224 & -4.11 & 5.66 & 0.19 \\
S4BF & 0.579 & 0.95 & 999.08 & 4.242 & -4.49 & 7.55 & 0.19 & 1.42 \\
S1 & 0.596 & 0.93 & 999.46 & 4.181 & -1.73 & 5.66 & 0.23 & -0.06 \\
S2 & 0.598 & 0.95 & 1001.50 & 4.178 & -1.31 & 7.55 & 0.44 & -0.12 \\
S3 & 0.601 & 1.00 & 1003.90 & 4.164 & -0.82 & 13.21 & 0.68 & -0.44 \\
S4 & 0.616 & 1.02 & 1005.10 & 4.145 & 1.62 & 15.09 & 0.80 \\
\hline
\end{tabular}

closest results (referred to as solidification heat) was determined to obtain the test result of the phase change experiments for the DSC.

Method 2 was performed using two isothermal units set at -12 and $25^{\circ} \mathrm{C}$. In this method, $12 \mathrm{ml}$ of the sample was loaded in a polypropylene (PP) test tube (capacity specification: $15 \mathrm{ml}$ ). A T-type thermocouple (accuracy: $\pm 0.75 \%$ or $\pm 0.5^{\circ} \mathrm{C}$ ) with a stainless steel protective tube (outer diameter: $0.6 \mathrm{~mm}$ ) was installed in the center of the PP test tube, and the contact location between the thermocouple and the lid of the PP test tube was fixed using epoxy. A $0.8 \mathrm{~mm}$ hole was made in the lid of the PP test tube to ensure pressure stability inside and outside. First, the sample was placed in an isothermal unit (P-20, YSC, Taiwan; accuracy: $\pm 0.5^{\circ} \mathrm{C}$ ) at $25^{\circ} \mathrm{C}$ to maintain the initial temperature of the sample at $25 \pm 0.5^{\circ} \mathrm{C}$; subsequently, the sample was transferred to another isothermal unit (TC-650SD, Brookfield, USA; accuracy: $\pm 0.5^{\circ} \mathrm{C}$ ) at $-12^{\circ} \mathrm{C}$ for the charging process. After the charging process was completed, the sample was relocated to an isothermal unit at $25^{\circ} \mathrm{C}$ for the discharging process. Once the sample reached $25 \pm 0.5^{\circ} \mathrm{C}$, the discharging process was completed. Temperature data of the phase change experiment for each sample were recorded using a data recorder (TRM-20, TOHO, Japan; accuracy: $\pm 0.1 \%$ ) at a sampling rate of $1.0 \mathrm{~s}$. Figure 4(b) illustrates the charging and discharging process curves for water determined using method 2. As shown in Figure 4(b), the time from the original temperature $\left(25^{\circ} \mathrm{C}\right)$ to $T_{\text {sub }}$, the time from $T_{\text {sub }}$ to the end of freezing, and the time from the start to the end of melting were referred to as the onset nucleation time (ONT), the solidification time (ST), and the melting time (MT), respectively. SD was defined as the difference between $T_{\mathrm{s}}$ and the $T_{\text {sub }}$. This experiment was conducted six times for each sample, and the average of the results was determined to obtain the phase change characteristics for each sample.

3.3. Data and Uncertainty Analysis. The experimental results are presented as a change ratio (CR) to reveal the differences between the experimental results of water $\left(D_{\mathrm{w}}\right)$ and those of the other samples $\left(D_{\mathrm{ts}}\right)$; CR can be expressed as

$$
\mathrm{CR}=\left[\frac{D_{\mathrm{ts}}-D_{\mathrm{w}}}{D_{\mathrm{w}}}\right] \times 100 \% .
$$

Uncertainty analysis entailed calculating deviations in the measurements. The uncertainty ranges determined for the fundamental characteristics of the samples, such as $k, \mu, \rho$, $c_{\mathrm{p}}$, and $\theta$, refer to deviations from the relevant measuring instruments and temperature controller. According to standard uncertainty analysis [42], the maximum uncertainty ranges for $k, \mu, \rho, c_{\mathrm{p}}$, and $\theta$ were within $\pm 5.39 \%, \pm 2.24 \%$, $\pm 2.00 \%, \pm 1.47 \%$, and $\pm 3.57 \%$, respectively. The temperature and calorimetric deviations of the phase change experiment conducted using the DSC were $\pm 0.1{ }^{\circ} \mathrm{C}$ and $\pm 1.0 \%$, respectively. Use of isothermal units for the phase change experiments required consideration of deviations resulting from the data recorder, thermocouple, and temperature controller; therefore, the maximum deviation was $\pm 2.14 \%$.

The temperature and calorimetric accuracies of the DSC were $\pm 0.1^{\circ} \mathrm{C}$ and $\pm 1.0 \%$, respectively.

\section{Results and Discussions}

Table 2 presents experimentally derived $k, \mu, \rho$, and $c_{\mathrm{p}}$ values of the samples. Regarding the measured $k$ values of the samples, the results revealed that adding SDBS to water engendered a reduction in the $k$ value of the water; moreover, the reduction ratio of $k$ was proportional to the SDBS concentration. However, adding MCMs of different concentrations to each base fluid (SDBS aqueous solution) tended to engender an increase in the $k$ values of the samples. The 0.48 wt.\% SDBS aqueous solution with 1.2 wt.\% MCMs (S4) increased $k$ by $1.62 \%$, compared with water. These experimental results demonstrate that although adding SDBS can improve the stability of a CBNF, it does not help to improve the $k$ value of the CBNF. However, the paramount performance index for a CBNF in energy storage applications is heat exchange. Therefore, considering the long-term useful life and feasibility of a CBNF, adding a dispersant is imperative. Moreover, $k$ is only one of the factors influencing heat transfer performance. In an actual heat exchange system, increasing the $k$ value of the working fluid has little effect on heat transfer performance.

Regarding the measured $\mu$ values of the samples, the results revealed that adding SDBS and MCMs to the base fluid increased the $\mu$ value of the base fluid; additionally, 


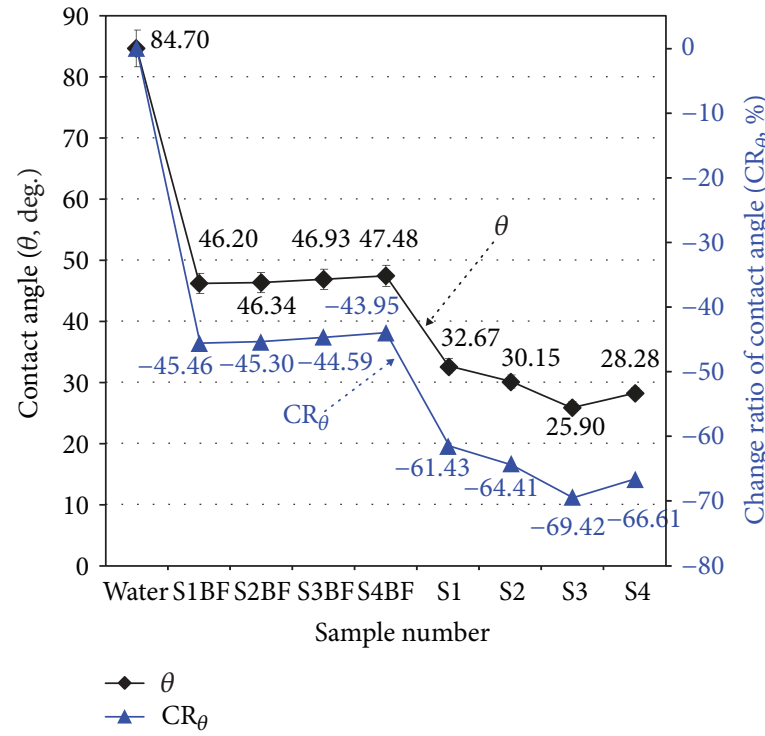

FIgure 5: Average value and CR of $\theta$ of each sample droplet.

the increase ratio of $\mu$ was proportional to the concentration of SDBS and MCMs. A CBNF belongs to a solid-liquid mixture. In general, a nanofluid has a higher $\mu$ value than that of a base fluid, and the increase ratio of $\mu$ is related to the particle size of the additives, solid-liquid interface characteristics, and stability. The $0.48 \mathrm{wt} . \%$ SDBS aqueous solution with 1.2 wt.\% MCMs (S4) increased the $\mu$ value by $15.09 \%$, compared with water.

Regarding the measured $\rho$ and $c_{\mathrm{p}}$ values of the samples, the results showed that adding SDBS and MCMs to the base fluid increased the $\rho$ value of the base fluid; moreover, the increase ratio of $\rho$ was proportional to the concentration of SDBS and MCMs. However, adding SDBS to water slightly increased the $c_{\mathrm{p}}$ value of the water, whereas adding MCMs slightly reduced the $c_{\mathrm{p}}$ value of the base fluid. MCMs are carbon-based materials and have higher $\rho$ and lower $c_{\mathrm{p}}$ values than those of water. According to the concept underlying a solid-liquid mixture, adding MCMs to water increases and reduces the $\rho$ and $c_{\mathrm{p}}$ values of the water, respectively. Due to the low concentration of SDBS and MCMs in this study, the effect on the $\rho$ and $c_{\mathrm{p}}$ values of the CBNF was not significant (the variation was within the uncertainty of the experiment). The $0.48 \mathrm{wt} . \%$ SDBS aqueous solution with 1.2 wt. $\%$ MCMs (S4) changed the $\rho$ and $c_{\mathrm{p}}$ values by $0.80 \%$ and $-0.92 \%$, respectively, compared with water. The results of the experiments on the fundamental sample characteristics confirm that adding SDBS reduced the $k$ value and increase the $\mu, \rho$, and $c_{\mathrm{p}}$ values of the samples, whereas adding the CBNFs tended to increase the $k, \mu$, and $\rho$ values and reduce the $c_{\mathrm{p}}$ value of the samples, compared with water.

Figure 5 illustrates the average and CR of $\theta$ for each sample droplet. As indicated in this figure, adding SDBS to water significantly reduced the $\theta$ values of the sample droplets, and adding MCMs to the SDBS aqueous solution further reduced the $\theta$ values of the sample droplets. The $\theta$ values of S1BF, $\mathrm{S} 2 \mathrm{BF}, \mathrm{S} 3 \mathrm{BF}, \mathrm{S} 4 \mathrm{BF}, \mathrm{S} 1, \mathrm{~S} 2, \mathrm{~S} 3$, and S4 were lower than

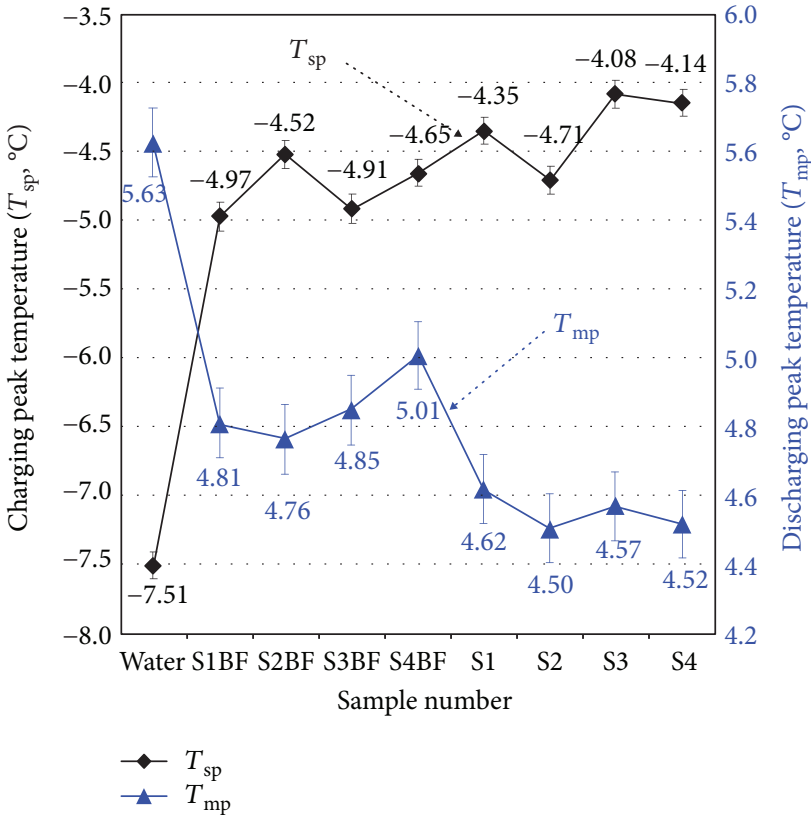

FIGURE 6: $T_{\mathrm{sp}}$ and $T_{\mathrm{mp}}$ for each sample in the experiment conducted using method 1 .

those of water by $45.46 \%, 45.30 \%, 44.59 \%, 43.95 \%, 61.43 \%$, $64.41 \%, 69.42 \%$, and $66.61 \%$, respectively. In addition, the influence of SDBS concentration on $\theta$ was less clear, compared with that of CBNF concentration. According to the aforementioned heterogeneous nucleation theory ((1) and (2)), the low $\theta$ values of the sample droplets contributed to the occurrence of freezing nucleation, facilitating PCM freezing [32, 35, 36].

Figure 6 shows the $T_{\text {sp }}$ and $T_{\mathrm{mp}}$ values obtained for each sample in the experiment conducted using method 1. Adding SDBS to water increased the $T_{\mathrm{sp}}$ value of the water, and adding MCMs to the SDBS aqueous solution further enhanced the $T_{\mathrm{sp}}$ value of the water. Although the experimental data presented a beating condition, the overall trend demonstrated an increase in $T_{\mathrm{sp}}$ with increasing SDBS and MCM concentrations. $T_{\mathrm{mp}}$ tended to gradually increase with SDBS concentration, whereas $T_{\mathrm{mp}}$ tended to decrease gradually with increased MCM concentration. However, the $T_{\mathrm{mp}}$ values of the aqueous SDBS and CBNF were lower than that of water throughout the experiments. A high $T_{\mathrm{sp}}$ helps to increase the temperature difference between the coolant of a chiller and the PCM at a fixed evaporation temperature to shorten the freezing time or enhance heat transfer capacity. A low $T_{\mathrm{mp}}$ provides a lower coolant temperature for the discharging process, thus engendering a higher temperature difference between the air-conditioning load and the coolant to increase the heat transfer capacity of the heat exchanger (fan coil units). Compared with water, the highest increase in $T_{\mathrm{sp}}$ was observed for $\mathrm{S} 3\left(3.43^{\circ} \mathrm{C}\right)$ and the highest reduction in $T_{\mathrm{mp}}$ was observed for $\mathrm{S} 2\left(1.12^{\circ} \mathrm{C}\right)$. The presented experimental results reveal that the $T_{\mathrm{sp}}$ and $T_{\mathrm{mp}}$ values of water were not near $0^{\circ} \mathrm{C}$ mainly because of the cooling and heating rates of the DSC. Cooling and heating rates affect the phase change condition; low heating and cooling rates result in water $T_{\mathrm{sp}}$ 


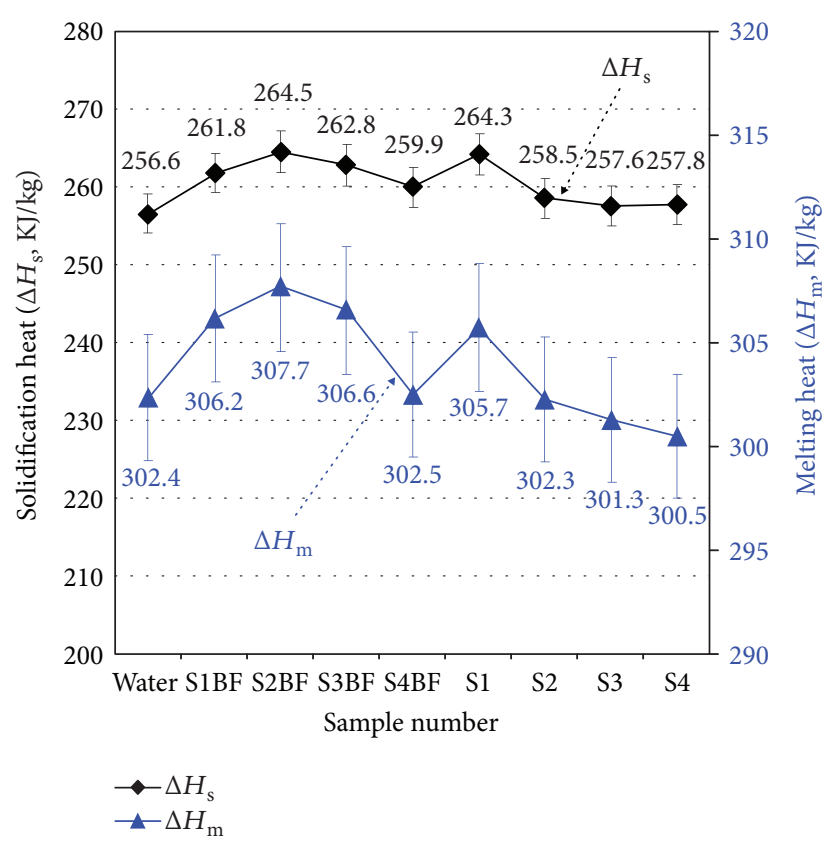

Figure 7: $\Delta H_{\mathrm{s}}$ and $\Delta H_{\mathrm{m}}$ for each sample in the experiment conducted using method 1 .

and $T_{\mathrm{mp}}$ values closer to $0^{\circ} \mathrm{C}$. However, excessively low cooling and heating rates result in longer measurement times that in turn lead to more severe sample weight loss and pressure changes within the sample pan, which can also cause measurement deviations. Therefore, in the present study, higher heating and cooling rates were used to conduct the DSC experiments to ensure relatively accurate measurements. A comparison of the relative differences between the various samples was made under the same experimental conditions.

Figure 7 displays the $\Delta H_{\mathrm{s}}$ and $\Delta H_{\mathrm{m}}$ values for each sample in the experiment conducted using method 1, indicating similar trends of $\Delta H_{\mathrm{s}}$ and $\Delta H_{\mathrm{m}}$. The $\Delta H_{\mathrm{s}}$ and $\Delta H_{\mathrm{m}}$ values increased and then decreased as the SDBS concentration increased; moreover, the values decreased as the MCM concentration increased. Overall, adding a small amount of SDBS (within 0.24 wt.\%) to water slightly increased the $\Delta H_{\mathrm{s}}$ and $\Delta H_{\mathrm{m}}$ values of the water. $\Delta H_{\mathrm{s}}$ less than $\Delta H_{\mathrm{m}}$ are mainly affected by the perfect degree of freezing crystallization of the samples, which is primarily influenced by the DSC cooling rates. PCMs with higher phase change heat can increase thermal storage density and thus reduce the volume of the thermal storage tank required under the same thermal storage capacity. However, in this study, the differences in phase change heat among all samples were not significant; the $\mathrm{CR}$ values of $\Delta H_{\mathrm{s}}$ and $\Delta H_{\mathrm{m}}$ relative to water were $0.39 \%-3.08 \%$ and $-0.03 \%-1.75 \%$, respectively. Therefore, all study samples would not be able to significantly contribute to increasing thermal storage density and reducing the volume of the thermal storage tank in an ice storage air-conditioning system.

Figure 8 illustrates the $T_{\mathrm{s}}$ and $T_{\mathrm{m}}$ values obtained for each sample in the experiment conducted using method 2, demonstrating similar variation trends for $T_{\mathrm{s}}$ and $T_{\mathrm{m}}$. Adding SDBS to water led to an increase in $T_{\mathrm{s}}$ and $T_{\mathrm{m}}$, which then decreased as the SDBS concentration increased;

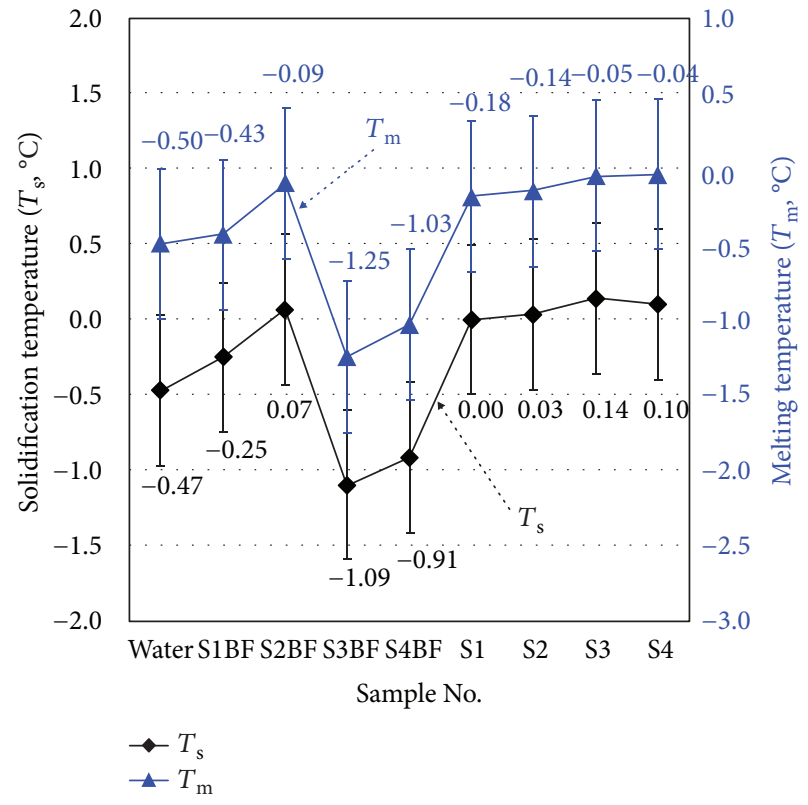

FIgURE 8: $T_{\mathrm{s}}$ and $T_{\mathrm{m}}$ for each sample in the experiment conducted using method 2 .

furthermore, adding MCMs to the SDBS aqueous solution induced a gradual increase in $T_{\mathrm{s}}$ and $T_{\mathrm{m}}$ as the MCM concentration increased. As mentioned $\left(T_{\mathrm{sp}}\right.$ and $\left.T_{\mathrm{mp}}\right)$, high $T_{\mathrm{s}}$ and low $T_{\mathrm{m}}$ contribute to the operational performance of ice storage air-conditioning systems. However, in this study, the applied SDBS aqueous solution and CBNFs had no significant effect on $T_{\mathrm{s}}$ and $T_{\mathrm{m}}$, and the largest difference relative to water was only $0.75^{\circ} \mathrm{C}$. Therefore, the SDBS aqueous solution and CBNFs would not significantly contribute to the operational performance of an ice storage air-conditioning system.

Figure 9 demonstrates the ONT, ST, and MT values for each sample in method 2. Adding SDBS and MCMs to water shortened the observed ONT of the water, but the reduction rate was not significantly related to the SDBS or MCM concentration. The highest reduction in ONT was observed for S4 (38.98\%), compared with water. The reduction in the water ONT after SDBS and MCM addition was mainly due to the decrease in SD that resulted in a shorter ice nucleation time. However, adding SDBS and MCMs to water did not necessarily shorten the water ST and MT, and the CR values of ST and MT were $-11.05 \%(\mathrm{~S} 4)-1.39 \%$ (S2BF) and $-10.05 \%(\mathrm{~S} 1)-5.39 \%$ (S3BF), compared with water. Shorter ST and MT can improve the charging efficiency and respond to the air-conditioning load capacity, respectively. The S4 and S1 samples had the highest ST and MT reduction ratios $(11.05 \%$ and $10.05 \%$, resp.) when compared with water.

Figure 10 displays the SD for each sample in method 1 and method 2. The SD values obtained from the experiments conducted using method 1 and method 2 differed considerably, but the two methods exhibited similar trends. The difference between the SD values can be primarily attributed to differences in the cooling rate. However, the SD values obtained through method 1 and method 2 both indicate that adding SDBS and MCMs to water reduced the SD 


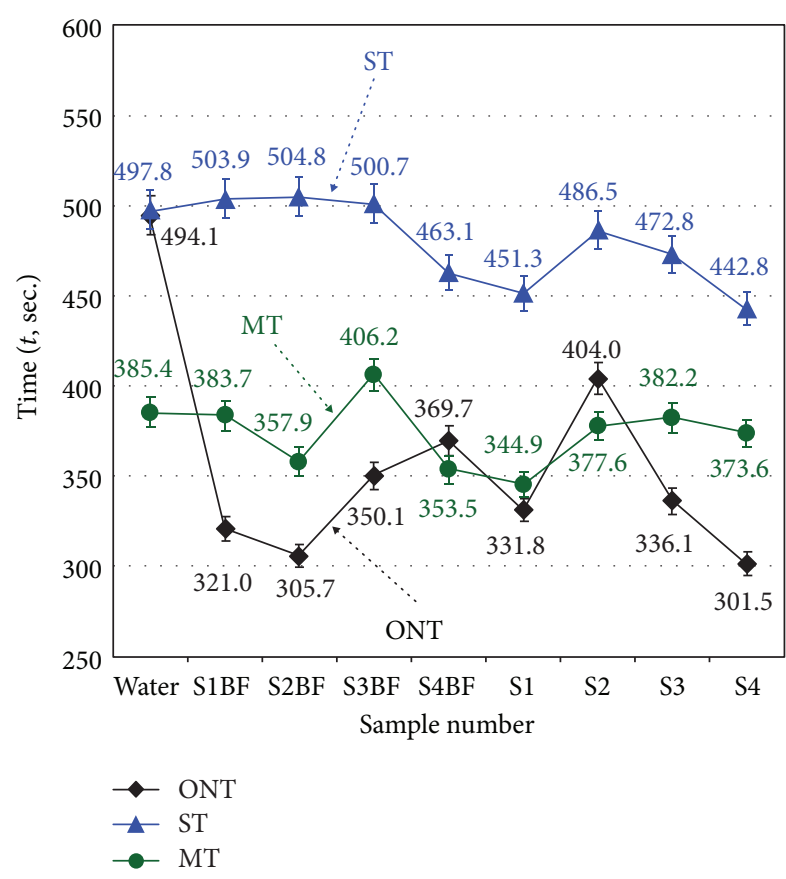

Figure 9: ONT, ST, and MT for each sample in the experiment conducted using method 2 .

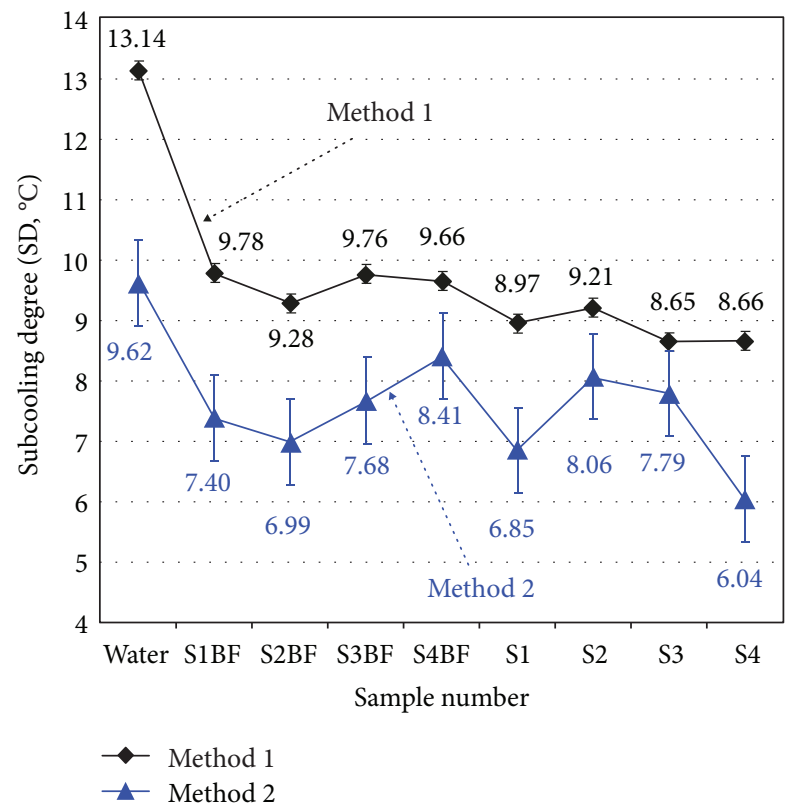

FIGURE 10: SD for each sample in the experiments conducted using both methods.

value of the water. This phenomenon is a result of three major factors:

(1) Adding SDBS and MCMs to water reduced the $\theta$ of the water between the sample and the substrate (increasing the wettability of the interface) and contribute to freezing nucleation $[6,12,35,36]$.
(2) MCMs act as nucleating agents.

(3) SDBS provides better suspension and dispersion performance for MCMs in water, which facilitates the transmission of energy to enhance the freezing phase change of CBNFs.

In both method 1 and method 2, S3 and S4 had the lowest SD $(-34.18 \%$ and $-37.23 \%$, resp.), compared with water. According to the average of the two test methods, the SD values of S1BF, S2BF, S3BF, S4BF, S1, S2, S3, and S4 were lower than those of water by $24.50 \%\left(2.79^{\circ} \mathrm{C}\right), 28.47 \%$ $\left(3.24^{\circ} \mathrm{C}\right), \quad 23.34 \% \quad\left(2.66^{\circ} \mathrm{C}\right), \quad 20.57 \% \quad\left(2.34^{\circ} \mathrm{C}\right), \quad 30.49 \%$ $\left(3.47^{\circ} \mathrm{C}\right), 24.10 \%\left(2.74^{\circ} \mathrm{C}\right), 27.76 \%\left(3.16^{\circ} \mathrm{C}\right)$, and $35.41 \%$ $\left(4.03^{\circ} \mathrm{C}\right)$, respectively. Based on the SD results obtained from the experiments conducted using method 1 and method 2, S4 demonstrated optimal SD suppression. According to the $\theta$ measurement results (Figure 6), the $\theta$ values of the CBNFs (S1-S4) were lower than those of the SDBS aqueous solution (S1BF-S4BF). However, not all CBNF samples had lower SD values than those of the SDBS aqueous solution. Such a finding can be attributed to the influence of particle size distribution and the stability of MCMs in CBNFs. The particle size distribution of MCMs is relatively broad when determined using both electron microscope images and DLS. Smaller specific surface areas of larger or aggregated MCMs provide a less heterogeneous nucleation interface area. In addition, large MCMs or aggregated MCMs are less stable and provide a relatively lower contribution to energy transfer. The interface effects and combination between water, SDBS, and MCMs are also crucial factors influencing the SD characteristics of CBNFs. The aforementioned factors affected the SD value of each sample to varying degrees. Overall, the effect of SD on the CBNFs was greater than that on the SDBS aqueous solution.

Based on the results, the ONT, ST, MT, and SD values of all CBNFs were significantly different from those of water, and ONT had a strong correlation with SD. In general, as a chiller's evaporation temperature increases by $1^{\circ} \mathrm{C}$, its power consumption decreases by $3 \%-5 \%$. Therefore, a low SD value helps improve the evaporation temperature of a chiller, thus considerably improving the chiller's operating efficiency. From the presented results, this study determined S4 to be the most suitable sample for use as a PCM in ice storage air-conditioning systems.

Figure 11 depicts a photograph of the four different concentrations of CBNF samples after 20 phase change experiments (method 2), revealing the stability of the CBNFs. Sedimentation from solid-liquid separation could not be observed even after the CBNFs underwent 20 repetitions of the charging and discharging processes. Therefore, the CBNFs in this study had considerable stability as a PCM for cold storage application.

\section{Conclusion}

CBNFs were prepared using a GP-HCPM, and SDBS was added as a dispersant to enhance the stability of the CBNFs. The fundamental characteristics of the CBNFs, suspended CBNMs, and SDBS aqueous solution were examined. Two 


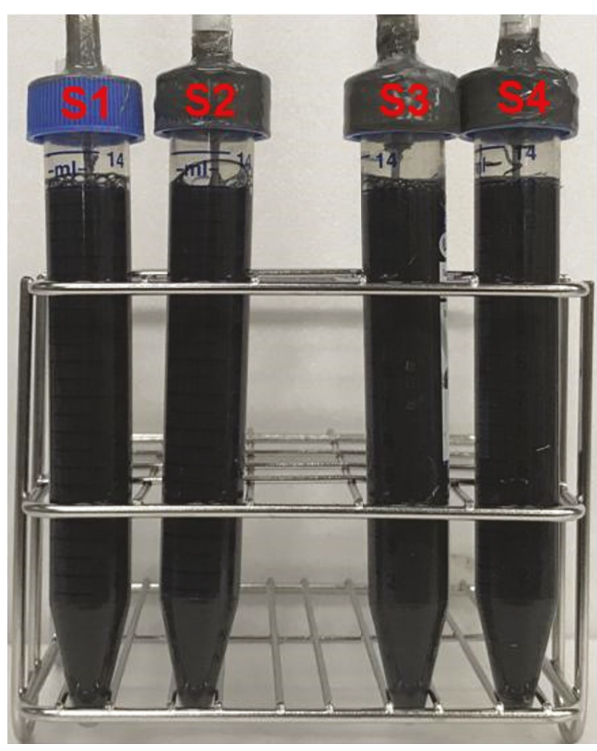

(a)

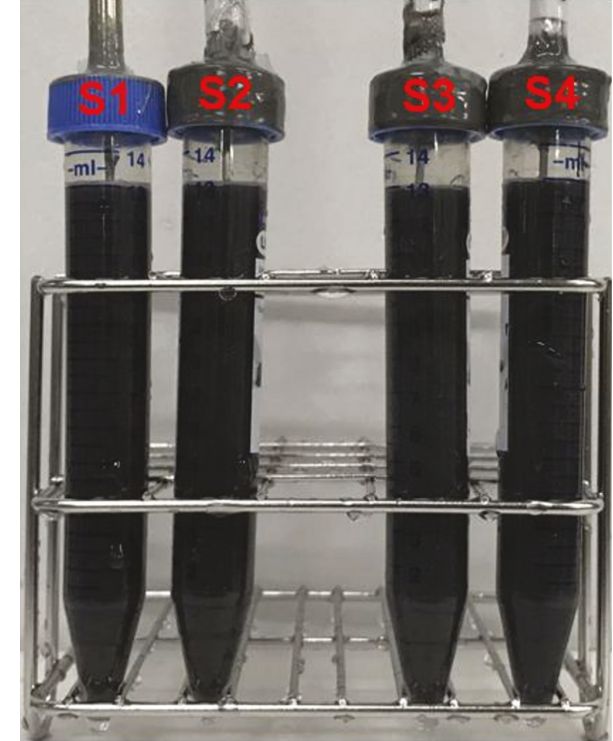

(b)

Figure 11: Photographs of the CBNF for (a) initial and (b) after undergoing 20 phase change experiments.

methods, one involving a fixed heating and cooling rate and the other involving a fixed heating and cooling temperature, were used to evaluate the feasibility of the CBNFs as PCMs for cold storage applications. The primary findings of this study are outlined as follows:

(1) The SDBS aqueous solution reduced the $k$ values and increased the $\mu, \rho$, and $c_{\mathrm{p}}$ values of the samples, and the CBNFs tended to increase the $k, \mu$, and $\rho$ values of the samples but tended to reduce the $c_{\mathrm{p}}$ values of the samples, compared with water. In all the test samples, the $k, \mu$, and $\rho$ of $S 4$ had the maximum increase ratio of $1.62,15.09,0.80 \%$, and $c_{\mathrm{p}}$ of $S 4$ had the maximum decrease ratio of $0.92 \%$ that compared with water.

(2) The SDBS aqueous solution and CBNFs significantly reduced $\theta$. The $\theta$ of SDBS aqueous solution and CBNFs had the maximum decrease ratio of $45.46 \%$ (S1BF) and $69.42 \%(\mathrm{~S} 3)$, compared with water.

(3) The CBNFs significantly reduced the ONT, ST, MT, and $\mathrm{SD}$ values, compared with water.

(4) The highest reductions in ONT, ST, and SD were observed for S4 $(38.98 \%, 11.05 \%$, and $35.41 \%$, resp.), compared with water.

(5) The CBNF sample S4 had the lowest ONT, ST, and SD of all the samples in the phase change experiments; thus, $\mathrm{S} 4$ was determined to be the most suitable CBNF for use as a PCM for cold storage applications.

\section{Data Availability}

The data used to support the findings of this study are available from the corresponding author upon request.

\section{Conflicts of Interest}

The authors declare that they have no competing interests.

\section{Acknowledgments}

The authors would like to thank the Ministry of Science and Technology of Republic of China (Taiwan) for their financial support to this research under Contract nos. MOST 104-2221-E-003-019-MY2 and MOST 106-2221-E003-021-MY3.

\section{References}

[1] Z. Kang, R. Wang, X. Zhou, and G. Feng, "Research status of ice-storage air-conditioning system," Procedia Engineering, vol. 205, pp. 1741-1747, 2017.

[2] B. Parsons, Design Guide for Cool Thermal Storage, ASHRAE, Atlanta, GA, Georgia, 1993.

[3] M. Faucheux, G. Muller, M. Havet, and A. LeBail, "Influence of surface roughness on the supercooling degree: case of selected water/ethanol solutions frozen on aluminium surfaces," International Journal of Refrigeration, vol. 29, no. 7, pp. 1218-1224, 2006.

[4] M. Keinänen, "Latent heat recovery from supercooled sodium acetate trihydrate using a brush heat exchanger, M.S. thesis," Department of Mechanical Engineering, Helsinki University of Technology, Finland, Europe, 2007.

[5] A. Safari, R. Saidur, F. A. Sulaiman, Y. Xu, and J. Dong, "A review on supercooling of phase change materials in thermal energy storage systems," Renewable and Sustainable Energy Reviews, vol. 70, pp. 905-919, 2017.

[6] S. Wu, D. Zhu, X. Li, H. Li, and J. Lei, "Thermal energy storage behavior of $\mathrm{Al}_{2} \mathrm{O}_{3}-\mathrm{H}_{2} \mathrm{O}$ nanofluids," Thermochimica Acta, vol. 483, no. 1-2, pp. 73-77, 2009.

[7] P. Chandrasekaran, M. Cheralathan, V. Kumaresan, and R. Velraj, "Solidification behavior of water based nanofluid 
phase change material with a nucleating agent for cool thermal storage system," International Journal of Refrigeration, vol. 41, pp. 157-163, 2014.

[8] X. Li, Y. Chen, Z. Cheng, L. Jia, S. Mo, and Z. Liu, "Ultrahigh specific surface area of graphene for eliminating subcooling of water," Applied Energy, vol. 130, pp. 824-829, 2014.

[9] Y. Liu, X. Li, P. Hu, and G. Hu, "Study on the supercooling degree and nucleation behavior of water-based graphene oxide nanofluids PCM," International Journal of Refrigeration, vol. 50, pp. 80-86, 2015.

[10] A. A. Altohamy, M. F. Abd Rabbo, R. Y. Sakr, and A. A. A. Attia, "Effect of water based $\mathrm{Al}_{2} \mathrm{O}_{3}$ nanoparticle PCM on cool storage performance," Applied Thermal Engineering, vol. 84, pp. 331-338, 2015.

[11] L.-W. Fan, X.-L. Yao, X. Wang et al., "Non-isothermal crystallization of aqueous nanofluids with high aspect-ratio carbon nano-additives for cold thermal energy storage," Applied Energy, vol. 138, pp. 193-201, 2015.

[12] L. Jia, L. Peng, Y. Chen, S. Mo, and X. Li, "Improving the supercooling degree of titanium dioxide nanofluids with sodium dodecylsulfate," Applied Energy, vol. 124, pp. 248255, 2014.

[13] T. Oya, T. Nomura, N. Okinaka, and T. Akiyama, "Phase change composite based on porous nickel and erythritol," Applied Thermal Engineering, vol. 40, pp. 373-377, 2012.

[14] P. Chandrasekaran, M. Cheralathan, V. Kumaresan, and R. Velraj, "Enhanced heat transfer characteristics of water based copper oxide nanofluid PCM (phase change material) in a spherical capsule during solidification for energy efficient cool thermal storage system," Energy, vol. 72, pp. 636-642, 2014.

[15] X. Zhang, X. Chen, Z. Han, and W. Xu, "Study on phase change interface for erythritol with nano-copper in spherical container during heat transport," International Journal of Heat and Mass Transfer, vol. 92, pp. 490-496, 2016.

[16] E. P. Ona, X. Zhang, S. Ozawa et al., "Influence of ultrasonic irradiation on the solidification behavior of erythritol as a PCM," Journal of Chemical Engineering of Japan, vol. 35, no. 3, pp. 290-298, 2002.

[17] E. P. Ona, S. Ozawa, Y. Kojima et al., "Effect of ultrasonic irradiation parameters on the supercooling relaxation behavior of PCM," Journal of Chemical Engineering of Japan, vol. 36, no. 7, pp. 799-805, 2003.

[18] U. Stritih, "An experimental study of enhanced heat transfer in rectangular PCM thermal storage," International Journal of Heat and Mass Transfer, vol. 47, no. 12-13, pp. 2841-2847, 2004.

[19] J. M. Khodadadi, L. Fan, and H. Babaei, "Thermal conductivity enhancement of nanostructure-based colloidal suspensions utilized as phase change materials for thermal energy storage: a review," Renewable and Sustainable Energy Reviews, vol. 24, pp. 418-444, 2013.

[20] V. Kumaresan, P. Chandrasekaran, M. Nanda, A. K. Maini, and R. Velraj, "Role of PCM based nanofluids for energy efficient cool thermal storage system," International Journal of Refrigeration, vol. 36, no. 6, pp. 1641-1647, 2013.

[21] S. Harikrishnan, S. Magesh, and S. Kalaiselvam, "Preparation and thermal energy storage behaviour of stearic acid- $\mathrm{TiO}_{2}$ nanofluids as a phase change material for solar heating systems," Thermochimica Acta, vol. 565, pp. 137-145, 2013.

[22] A. Zabalegui, D. Lokapur, and H. Lee, "Nanofluid PCMs for thermal energy storage: latent heat reduction mechanisms and a numerical study of effective thermal storage performance," International Journal of Heat and Mass Transfer, vol. 78, pp. 1145-1154, 2014.

[23] X. Zhang, J. Niu, S. Zhang, and J. Y. Wu, "PCM in water emulsions: supercooling reduction effects of nano-additives, viscosity effects of surfactants and stability," Advanced Engineering Materials, vol. 17, no. 2, pp. 181-188, 2015.

[24] R. Al-Shannaq, J. Kurdi, S. Al-Muhtaseb, M. Dickinson, and M. Farid, "Supercooling elimination of phase change materials (PCMs) microcapsules," Energy, vol. 87, pp. 654-662, 2015.

[25] S. I. Golestaneh, A. Mosallanejad, G. Karimi, M. Khorram, and M. Khashi, "Fabrication and characterization of phase change material composite fibers with wide phase-transition temperature range by coelectrospinning method," Applied Energy, vol. 182, pp. 409-417, 2016.

[26] C.-S. Heu, S.-W. Kim, K.-S. Lee, and D.-R. Kim, "Fabrication of three-dimensional metal-graphene network phase change composite for high thermal conductivity and suppressed subcooling phenomena," Energy Conversion and Management, vol. 149, pp. 608-615, 2017.

[27] M. M. Farid, A. M. Khudhair, S. A. K. Razack, and S. Al-Hallaj, "A review on phase change energy storage: materials and applications," Energy Conversion and Management, vol. 45, no. 9-10, pp. 1597-1615, 2004.

[28] F.-C. Li, J.-C. Yang, W.-W. Zhou, Y. R. He, Y. M. Huang, and B. C. Jiang, "Experimental study on the characteristics of thermal conductivity and shear viscosity of viscoelastic-fluidbased nanofluids containing multiwalled carbon nanotubes," Thermochimica Acta, vol. 556, pp. 47-53, 2013.

[29] M. Soltanimehr and M. Afrand, "Thermal conductivity enhancement of $\mathrm{COOH}$-functionalized MWCNTs/ethylene glycol-water nanofluid for application in heating and cooling systems," Applied Thermal Engineering, vol. 105, pp. 716723,2016

[30] D. Huang, Z. Wu, and B. Sunden, "Effects of hybrid nanofluid mixture in plate heat exchangers," Experimental Thermal and Fluid Science, vol. 72, pp. 190-196, 2016.

[31] Y.-H. Hung, W.-P. Wang, Y.-C. Hsu, and T.-P. Teng, "Performance evaluation of an air-cooled heat exchange system for hybrid nanofluids," Experimental Thermal and Fluid Science, vol. 81, pp. 43-55, 2017.

[32] R. P. Sear, "Nucleation: theory and applications to protein solutions and colloidal suspensions," Journal of Physics: Condensed Matter, vol. 19, no. 3, article 033101, 2007.

[33] X.-J. Wang, X. F. Li, Y. H. Xu, and D. S. Zhu, "Thermal energy storage characteristics of $\mathrm{Cu}-\mathrm{H}_{2} \mathrm{O}$ nanofluids," Energy, vol. 78, pp. 212-217, 2014.

[34] E. Günther, L. Huang, H. Mehling, and C. Dötsch, "Subcooling in PCM emulsions- part 2: interpretation in terms of nucleation theory," Thermochimica Acta, vol. 522, no. 1-2, pp. 199-204, 2011.

[35] R. P. Sear, "Quantitative studies of crystal nucleation at constant supersaturation: experimental data and models," CrystEngComm, vol. 16, no. 29, pp. 6506-6522, 2014.

[36] C. A. Sholl and N. H. Fletcher, "Decoration criteria for surface steps," Acta Metallurgica, vol. 18, no. 10, pp. 1083-1086, 1970.

[37] T.-P. Teng, J.-Y. Li, and W.-P. Wang, "Preparation and characterization of carbon-based nanofluid through a heating and cooling processing method," in Asian Conference on Engineering and Natural Sciences (ACENS 2016), pp. 150159, Fukuoka, Japan, February 2016, ID: ACENS-8908. 
[38] T.-C. Hsiao, T.-P. Teng, J.-Y. Li, and C.-Y. Yu, "Effect of temperature on the characteristic of carbon-based nanofluid," in Tokyo 14th International Conference on Engineering \& Technology, Computer, Basic \& Applied Sciences (ECBA2017), Tokyo, Japan, March 2017ID: TKE-537-102.

[39] R. Greenwood and K. Kendall, "Selection of suitable dispersants for aqueous suspensions of zirconia and titania powders using acoustophoresis," Journal of the European Ceramic Society, vol. 19, no. 4, pp. 479-488, 1999.

[40] D. Hanaor, M. Michelazzi, C. Leonelli, and C. C. Sorrell, "The effects of carboxylic acids on the aqueous dispersion and electrophoretic deposition of $\mathrm{ZrO}_{2}$," Journal of the European Ceramic Society, vol. 32, no. 1, pp. 235-244, 2012.

[41] ASHRAE, "Chapter 30 Thermophysical properties of refrigerants," in ASHRAE Handbook-Fundamentals (SI), pp. 30.130.75, ASHRAE, Atlanta, GA, Georgia, 2009.

[42] H.-M. Nieh, T.-P. Teng, and C.-C. Yu, "Enhanced heat dissipation of a radiator using oxide nano-coolant," International Journal of Thermal Sciences, vol. 77, pp. 252-261, 2014. 


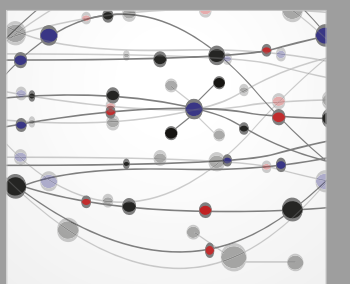

The Scientific World Journal
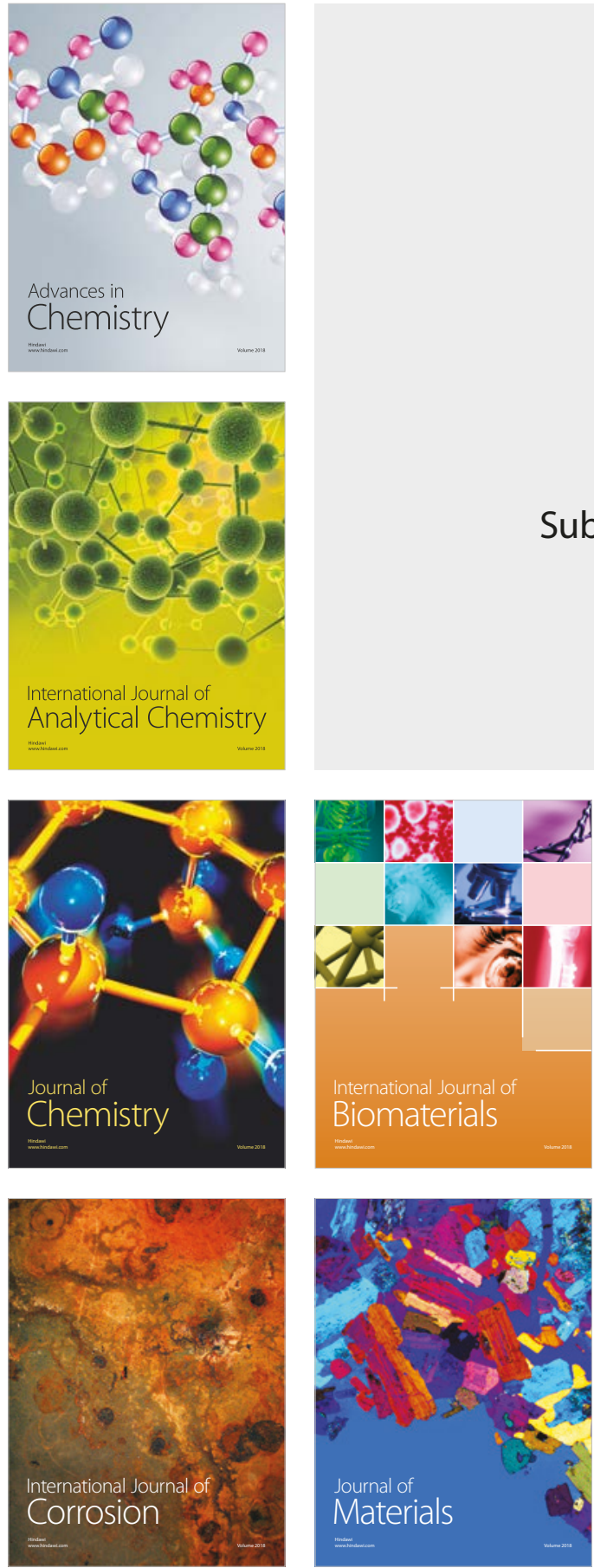

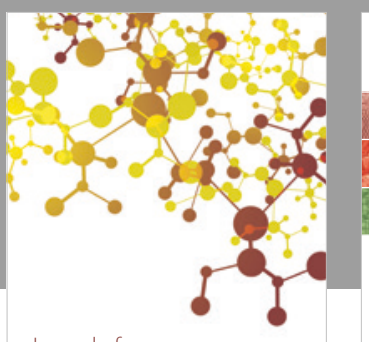

Journal of

Applied Chemistry
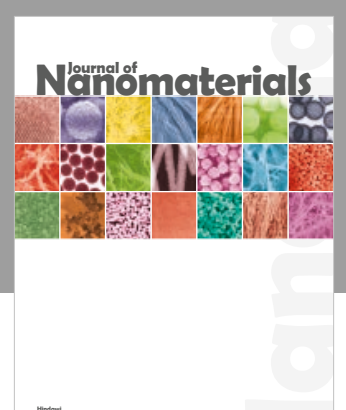

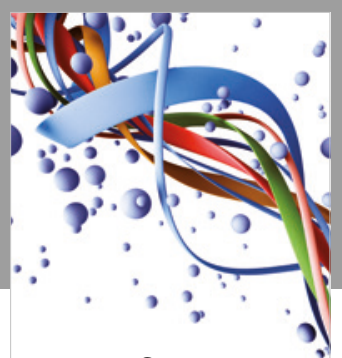

Scientifica

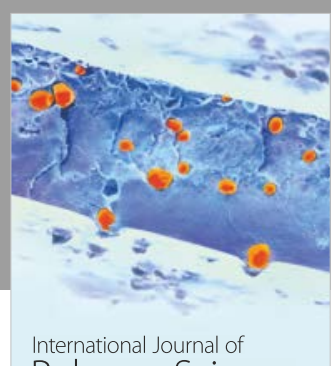

Polymer Science

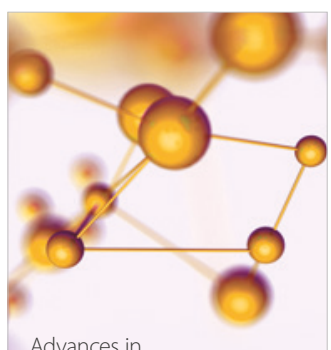

Physical Chemistry
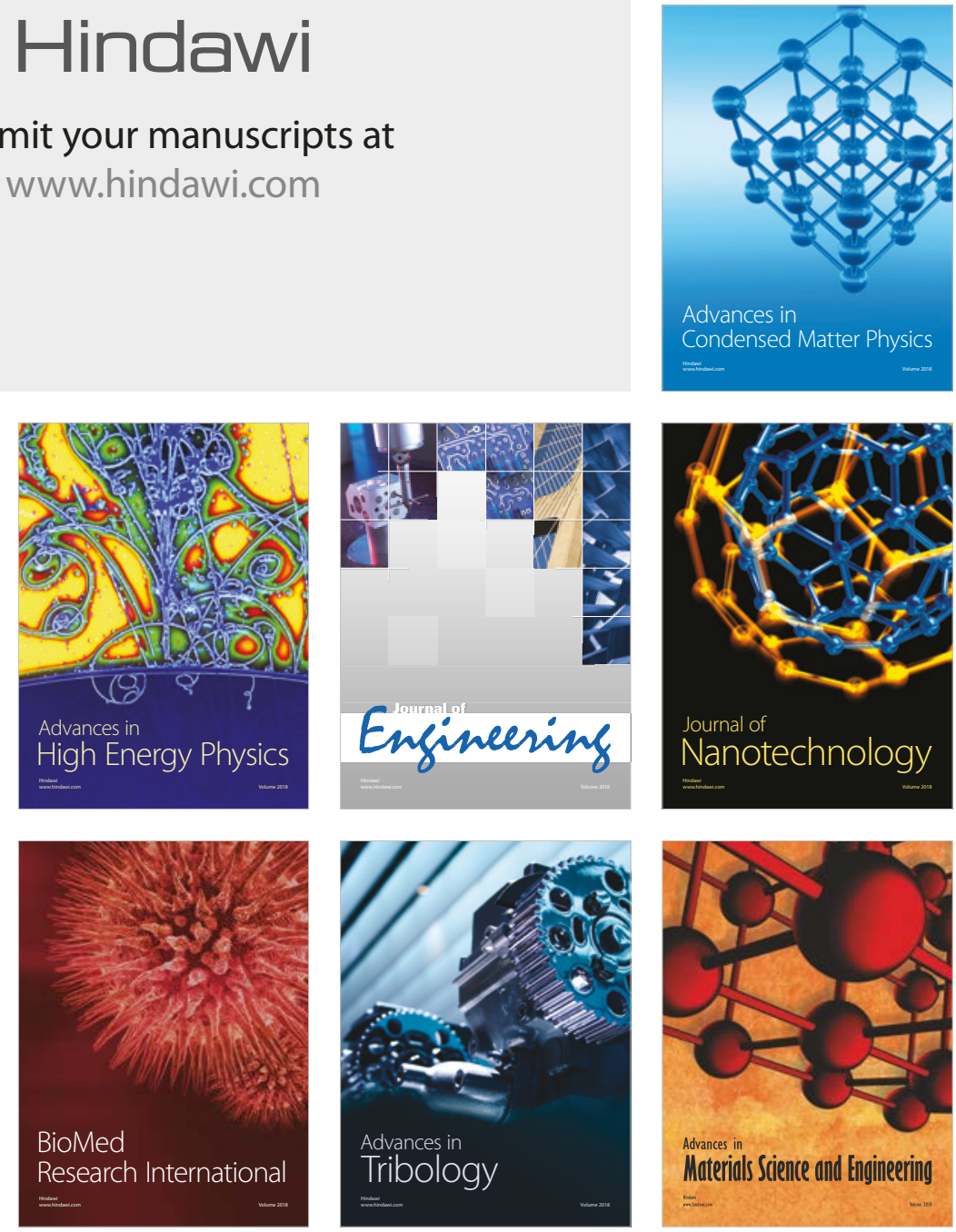